A suture uniting the superior and inferior margins of the conjunctiva introduced; a rondelle of antiseptic cotton wool previously moistened with distilled water is inserted between the lids and a compressive bandage applied, and permitted to remain for twenty. four or thirty-six hours.

The stitches uniting the superior and inferior margins of the conjunctiva are generally removed on the second day following the enucleation.

The following operation has been suggested a decade or more ago and appears to possess the important advantages derived from the operation of enucletion with none of the disadvantages of that of evisceration, as proposed by Mr. Mules, or other "operations" that do not materially differ from evisceration other than as to the method in removing a little more or less of nerve tissue, and the dangers arising from sympathetic trouble being almost nil when compared to the so-called surgical interferences that permit the retension of a portion of the structures of a globe that has already become or is liable to take on disease at any moment.

The operation is similar or in fact is practically identical with that of enucleation with the addition of a sterilized hollow glass sphere (to avoid the dangers of a sphere becoming fractured one made of silver or aluminum has been suggested as a likely substitute) is inserted into the cavity of Tenon's capsule and the conjunctiva stitched firmly over it; a temporary catgut drain will have to be used in conjunction with the operation.

When the eyeball is entirely removed as in this operation there is no likelihood of disease being propagated and thereby displacing the questionable practice commended by a writer in an article of a late date, of the "ingrafting" into the tissues of the orbital cavity portions of so dangerous a substance as the "deadly" sepsis-generating sponge, to act as a "support" for an artificial eye.

Advocates of "substitutes" for enucleation who, for reasons of their own, appear unable to obtain a proper support for an artificial eye following their enucleations, will find a useful and movable support, as the muscles of the eyeball are attached upon the sphere inclosed within it; as Tenon's capsule is attached to the conjunctiva in front, when this is sutured the capsule is rendered tense and becomes accurately adapted to the selected sphere. This operation, however presents some disadvantages.

The operation of enucleation is wonderfully benign and if carefully performed does not in the least interfere with the adjustment of an artificial eye, whose motility will be as perfect as if resting upon a shrunken globe, besides being free from the dangers of a shrunken remnant of a lost eye, acting in the same prejudicial manner as an injured or diseased eye before having parted with its contents or a portion of its structures. A most happy effect is gained by enucleation, in arresting and subduing the irritation which threatens to develop into destructive inflammation of the sound eye.

Enucleation at an early stage should be insisted upon where eyes have been crushed by blows, that are the site of neoplastic growths that may prove malignant; eyes that have been penetrated by foreign bodies which are not removable, which belong to patients who can not be trusted to take either proper care of themselves or to return if they are threatened with sympathetic irritation.
When the exciting eye is evidently remlered useless by the wound or from consequent inflammation, that is when its vision amounts to perception of light, and when there is no probability that sight will improve without incurring the risks of the sympathizing eye, the exciting eye should immediately bo excised. If the sympathizing eye is only suffering from irritation and presents no symptoms of inflammation the removal of the exciting eye will be followed by immediate relief of the irritation and no symptoms of inflammation are likely to appear; hence the necessity of an early enucleation of useless eyeballs from persons in whom one sound eye remains as a prophylatic measure. Advocates of such "operations" as abscission, neurotomy, optico-ciliary neurotomy, exenteration or substitutes of a like character that permit the retension of a portion of a diseased globe, can hardly advance any claim to merit, save to afford only temporary relief from sensitive and painful eyeballs without offering the least safeguard to the prevention of sympathetic phenomena or destructive inflammation of the sound or remaining eye.

The operation of enucleation should alone be practiced, and the "substitute" procedures adopted and advocated every now and then by some youthful or experimental surgeon, inhibited by law.

3907 West Belle Place.

\section{A NEW SPLINT FOR NASAL FRACTURES AND DEFORMITIES.}

Read at tbe Third Annual Meeting of the American Academy of Railway Surgeons, held at Chicago, Sept. 23, 24 and $25,1896$. BY JESSE HAWES, M. D., DIVISION SURGEON ON THE TNION PACIFIC, DFNYER AND GULF RAILWAY,
GREELET, COIO.

This splint is intended for cases of nasal fracture in which there is a drawing upward of the point of the nose or of the alæ. Permit me to describe it by the narration of a case in which necessity demanded it

C. W., boy aged 10 years, was brought to me, having been kicked by a horse several days before. The toe of the animal struck the nasal septum at its junction with the upper lip. The blow cut the septum loose from the lip. A wound extended through the septum from the point of union with the lip directly upward for three-fourths of an inch.

The detached edge of the septum was rolled up into the nose; both alæ were forced upward; the nasal bones were detatched from the maxillary and driven upward, and small pieces of the maxillary were broken on each side of the nose. The contractions of the levators of the nose held the soft and hard tissues where they had been driven by the kick. The point of the nose was far above its normal position; the right ala was much higher than the left.

The first step toward repair must be to bring down and fasten the septum in its position, the next to replace the fractured bones, the last to bring down and retain in position the upturned nose. To fasten the septum by stitches was simple; the nasal bones were easily pressed into their normal position, but slipped outward as soon as manual pressure was removed. To bring down and retain the point of the nose in its proper place was impossible.

The best suggestion I could get from " the books" and experience was to draw the nose down by grasping its point, then to transfix the lower end of the 
septum antero-posteriorly with a long, stout, steel splint than it could have been by using any splint needle, the point of which was driven down in the that has preceded it; indeed there is no appliance, so palatal process of the superior maxillary. (See illus- far as I can learn, that can perform the office of this. trations in Roberts' Surgery.) While this partially I have recently added to the appliance a means of held the point of the nose from being drawn upward, elevating depressed portions of the nose and perit did so very imperfectly; the upward dislocation of manently retaining them in position. It consists of a the alæ was corrected but very little. The quite wire of spring brass, bent so as to elevate the depresrecent editions of Bryant, Keene, Ashhurst, Stephen sion to the normal position by pressing upward from Smith, Wyeth, Roberts, Ashhurst's Cyclopedia, Ham. ilton's Fractures, Holmes, Gross and Stimson offered no helpful suggestion.

After several days of chagrin over my inability to control the deformity, the very simple nasal appliance which I here present suggested itself.

It consists of a piece of No. 15 spring brass wire of suitable length. bent first into the form of a rectangular letter $\mathrm{C}$, the arms of which are about an inch apart and long enough to extend from the center of the upper lip to the crown of the head or beyond that point; opposite the supra-orbital ridge a sharp angle is formed; this angle is to permit the splint to enter the orbital cavity just beneath the orbital ridge; this angle is a means of fixation of the splint against the supra-orbital ridge and is one of the most essential features of the appliance. The lower end of the splint - $i$. e., the transverse portion - is carried forward, away from the lip, the distance of a half inch.

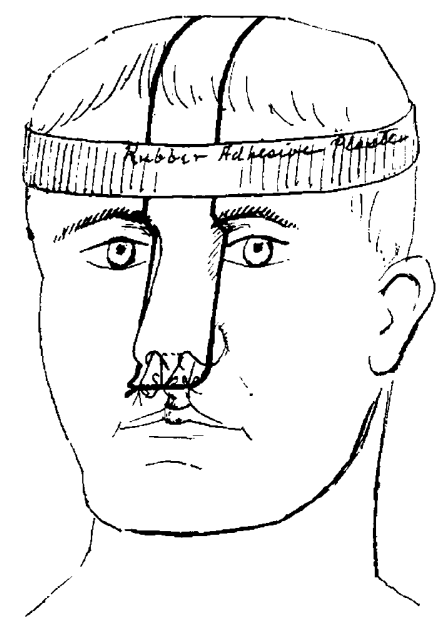

A continued narration of the case will best illus. trate the application of the appliance: Having formed the wire splint to fit the head, forehead and nose of my patient it was applied to these parts; a folded piece of lintine was placed between the wire and the orbital ridge to prevent painful pressure at that point; the splint was held firmly in contact with the head with a broad strap of rubber adhesive plaster carried across the forehead and completely around the head.

The nasal bones, which could only be held in position by continuous pressure, were easily retained by pads of lintine placed between the splint and the side of the nose. A large, strong silk suture was carried through the septum near the point of the nose, the nose was pulled down by tying the ligature to the transverse wire beneath. The mucous membrane and cartilage (but not the skin) of each of the alæ were pierced by similar ligatures, and when drawn down to their proper positions the ligatures were fastened to the wire beneath.

The result in my case was eminently satisfactory though not perfection and was far better with this the inside of the nose. The wire should be covered with soft-rubber tubing; the stiffness of the wire should ordinarily be less than that of the outside splint. Each intra-nasal wire can be firmly fixed to the lower angle of the splint by a simple mechanical arrangement. This permits the intra-nasal wire to be removed from the nose and from the splint when necessary to change its form or pressure. I have experimented with these intra-nasal attachments and believe that when properly fitted to the inner surface of the nose they will raise the depressed part and retain it in position more satisfactorily than any other device heretofore offered. The splints are manufactured by Chas. Truax \& Co., 75 Wabash Avenue, Chicago.

Let me recapitulate the advantages of the appliance: 1. They are simple; the first described appliance can be made in a few minutes by any surgeon who has the wire and a pair of suitable forceps.

2. It is easily applied, remains permanently in position and permits the organ to be inspected during the progress of recovery.

3. It holds a compress firmly to the side of the nose when such are needed to correct deviations, an important matter in some cases.

4. It will draw down the point of the nose or the alæ and hold them firmly in their normal position. No other appliance for accomplishing this has heretofore been presented to our profession.

$\tilde{5}$. The intra-nasal wires, when used, remain where placed, a statement that is not true of the intra-nasal plugs ordinarily used, such as cloth-cotton, rubber tubes, etc.

6. I suggest the use of the intra-nasal splint in restoring the normal esthetic shape and overcoming the deformities of noses long previously fractured, after vicious adhesions and unions have been broken up.

Dr. E. M. Dooley, Buffalo-I think, as I have served as a lay figure for the demonstration of this apparatus, it is my privilege to speak on this subject, and I would like to state for the benefit of those who have had no experience with the splint, that my experience was extremely pleasant; in other words, it was quite comfortable as long as I had it on-but whether the inside is as comfortable or not I have my doubts. But I think from my experience with broken noses, and owing to the locality in which I live I have had a great deal of experience with broken noses, and I have of ten been at a loss to have a splint that would do in any and all cases, and I feel very thankful to Dr. Hawes for exhibiting this splint, and I shall use it in the next case where I think it will be of service.

Dr. Kibler, Cory, $\mathrm{Pa}$.---Justone matter that occurred to me in connection with the splint, and that is-I am glad that Dr. Dooley testifies to the fact that the splint is a good one-could that part that enters the nose be made of hard rubber? It could be made more thoroughly aseptic and I believe give less danger to the mucous surfaces than you could have from the brass wire.

Dr. Hawes-It probably slipped your attention that that is covered with a soft rubber catheter.

Dr. LEMEN, Denver-As this originated in my neighborhood, Dr. Hawes being a neighbor of mine, and I was being occasion. ally asked to treat broken noses, he insisted that I use it, and I have used it in a number of cases and am very much pleased
with its application; it holds the position of the bones per. 
fectly. If the surgeon's apposition is properly attended to, the same is continued by the application of the splint.

Dr. Cole, Helena-It strikes me as being an extremely ingenious device. In the entire field of accidental surgery in minor matters there is nothing more troublesome, perhaps, than fracture of the nose with displacement, and to get a satisfactory result is sometimes exceedingly difficult, and if I understand rightly the application of this apparatus it should be a practical part of every surgeon's paraphernalia.

Dr. W. J. MAYO, Rochester, Minn.-I was very much inter ested in the splint of the Doctor, the external part I have never seen used in this connection. My brother, Dr. C. H. Mayo, has used a somewhat similar intra nasal splint in the elevation of depressed nasal fractures, and also a method of his own for the relief of sunken nose caused either by fracture or specific disease. In sunken nose he cuts obliquely through the septum and the depressed tissues behind and inside of the nose with a heavy chisel or cartilage knife, and elevating the septum introduces the splint, which allows sound union at a high level. In these cases the results have been excellent and continued so. Ths bevel of the cut surface enables the sliding upward of the depressed portion. The splint used by him consists of a similar piece of brass wire bent by a single turn into a coil, the two projecting ends being introduced into the nostrils, one along the floor the other sprung up beneath the depression; the tension of the spring thus formed gives the necessary upward curve, one splint thus constructed and covered with iodoform gauze being introduced into each side and left for a number of days.

Dr. BRyant, Omaha - I think this invention of Dr. Hawes for holding down the nose after an injury, not only the best splint I have seen, but the only one. I have never seen one for this particular purpose. The difficulty in a majority of the cases where injury to the nose has been received, is not to hold the nose down, but to raise it up-probably 90 per cent. or more would have a depressed nose, instead of an elevated nose : but this seems to be an all-round splint, not only to hold it down but to elevate it. If I were to criticise this I think it would be in the portion that enters the nostril, and that criticism is not anything of value, it simply would be this: In many cases, make it larger in order to keep it in, and that could be done by winding the copper with thread or string and then using soft rubber over that. I believe soft rubber is the best thing to prevent irritation of the mucous membrane, and I think this [indicating] might be uncomfortable after using it any length of time-that is, I think it would.

Dr. HAwEs--In making some remarks upon the comments that have been made $I$ come first to the comment that the inside appliance is uncomfortable. Any man that has ever had any experience knows that nothing is very comfortable in the nose; whenever you push up there a lot of cotton or cloth it is uncomfortable--but that has hardly ever been an objection during the years it has been practiced; it would be customary to use a wad of cotton, which is a thousand times more uncomfortable than the other, which is much more efficient. One of the other criticisms was on account of using a hard brass substance that was liable to corrode. That I reply to with the statement that in the paper it was stated it should be covered with a soft rubber catheter. I want to call attention to another fact, that I have presented to you two splints, the second is an outgrowth of the first; the second can be used for all purposes that the first was used for, the first can not be used for the purpose for which the second is. The first is intended to draw down the nose when it has been drawn upward: the second is intended to raise the nose from the inside, which is wholly outside of the field intended as the proper field of the first. Dr. Mayo speaks of a method which I was not aware of ; I have never seen it mentioned in the books. It is very evidently an excellent method of raising these depressed noses. This one of mine, while I have never had an opportunity to raise depressed noses, I have no doubt will do exactly what the other one does. The person who is using the splint should have some knowledge of the anatomic form of the inside of the nose, and should then bend his wires so that they should fit that form in particular, and raise the nose to its normal and esthetic position. The comment of Dr. Bryant that it should be larger can be very easily attained by using a larger catheter instead of the little catheter--I peeled off and threw away the rubber that I had on the outside when I began to talk, to show you the wire. By using the larger catheter you can adapt it on the inside to a nose of any size that you desire. Another of our members inquires, Where can I get these splints? I have stated in the paper that all you have to do is to get a piece of wire and a pair of pincers. If you want something better you might go down to any of the instrument makers, or even to the common tinsmith, and by giving your deas, you might get it made in a very few minutes---if you go to the instrument maker it will cost you a dollar and a half; if you go to the tinsmith it will cost you ten cents. That Th.

The President - Can the surgeon readily make that second splint?

Dr. HAwES-I made one; I am not a tinker or son of a tinker. but I made one in a bungling sort of way. This I took to the tinker and asked him to make it, and he made it rather better. shapelier far than I can; you would have to take that second one to the tinker or tinsmith or instrument maker. I do not think it is wholly perfect, but that it is an embryo of a valuable instrument, a valuable appliance.

Dr. Reinenind, Sheboygan, Wis. - I would like to make a suggestion in regard to the enlargement of the intranasal portion. I think that can be done and made comfortable by winding around absorbent cotton and dipping that in melted parafin which can be impregnated with an antiseptic solution; a back ing of cotton cloth can be built up on the intranasal splint the parafin is hard enough to make sufficient pressure.

Dr. HARNDEN, Waverly, N.Y.--I think it would be in order that a vote of thanks of this Academy be extended to the Doctor for bringing to our attention the valuable instrument.

Motion seconded and unanimously carried.

\section{REMARKS ON THE TREATMEN'T OF FRACTURES.}

I ade at the Third Annual Meeting of the American Academy of Rail. way Surgeons, held at Chicago, Ill., Sept. $23,24,25,1896$. BY R. ORTEGA, M.D.

(HIEF SURGEON TO THE MFXICAN INTERNATIONAL RAILWAY CIUDAD PORFIRIO DIAZ, MEXICO.

I want to talk about a treatment or practice which gives the patient entire relief at once from pain and puts him in good condition for work as soon as the fracture is solid. As soon as a patient breaks a bone I make massage from the lower part of the fractured limb to the upper part; we commence to do the massage very gently just on the skin, with anything, oil, or soap and water, salve or vaselin to allow the hand to rub without hurting. Ten or fifteen minutes afterward we do the massage on the muscles, always from the end of the member up, never making pressure; in ten or fifteen minutes after the pain is gone and we can reduce the fracture without chloroform or pain. As soon as the fracture is reduced we roll it in a simple flannel bandage, from the end of the member upward; if it is in the arm we put the arm in a simple handkerchief from the neck; if it is in the upper arm, the weight of the arm is enough to keep the fracture in good position. And the next day we do the same treatment, a little massage and a little movement in all the joints of the broken limb. I have done this treatment for a year. I have had but few cases as my practice is very small. One boy about 18 years old, had a wheel from which he fell and broke his right arm in the middle with a compound fracture, the upper end of the humerus projecting through the skin. Dr. Lord reduced this fracture, put on a good dressing and an apparatus, and he called the next day to see the patient; the patient wanted to cross the river. I saw the boy with Dr. Lord; we took off the apparatus, the wound was in good condition, aseptic because the doctor had put a very nice and good dressing on. I told him I was going to take off the apparatus as soon as I brought the boy over the river. I did so and then applied a bandage, and made motion in the elbow and other joints and in fifteen days this boy was at work as before the injury. There was a compound fracture of the humerus and simple fracture of the ulna, and in fifteen days later the boy recovered and worked as before, all the bones completely healed. I had one day two cases; one a smali 